\title{
Collapsin Response Mediator Protein 1 Mediates Reelin Signaling in Cortical Neuronal Migration
}

\author{
Naoya Yamashita, ${ }^{1}$ Yutaka Uchida, ${ }^{1}$ Toshio Ohshima, ${ }^{4}$ Syu-ichi Hirai, ${ }^{2}$ Fumio Nakamura, ${ }^{1}$ Masahiko Taniguchi, ${ }^{5}$ \\ Katsuhiko Mikoshiba, ${ }^{4}$ Jérôme Honnorat, ${ }^{6}$ Pappachan Kolattukudy, ${ }^{7}$ Nicole Thomasset, ${ }^{6}$ Kohtaro Takei, ${ }^{1,8}$ \\ Takuya Takahashi, ${ }^{3}$ and Yoshio Goshima ${ }^{1,8}$ \\ Departments of ${ }^{1}$ Molecular Pharmacology and Neurobiology, ${ }^{2}$ Molecular Biology, and ${ }^{3}$ Physiology and Neuroendocrinology, Yokohama City University \\ Graduate School of Medicine, Yokohama 236-0004, Japan, ${ }^{4}$ Laboratory for Developmental Neurobiology, Brain Science Institute, The Institute of Physical \\ and Chemical Research, Wako 351-0198, Japan, 50partment of Biochemistry, Cancer Research Institute, Sapporo Medical University, Sapporo 060-8556, \\ Japan, ${ }^{6}$ Institut National de la Santé et de la Recherche Médicale Unité 433, Institut Federatif des Neurosciences de Lyon, Hôpital Neurologique, F-69003 \\ Lyon, France, ${ }^{7}$ Biomolecular Science Center, University of Central Florida, Biomolecular Science, Orlando, Florida 32816, and ${ }^{8}$ Core Research for \\ Evolutional Science and Technology, Japan Science and Technology Agency, Kawaguchi 332-0012, Japan
}

Collapsin response mediator protein 1 (CRMP1) is one of the CRMP family members that mediates signal transduction of axon guidance molecules. Here, we show evidence that CRMP1 is involved in Reelin (Reln) signaling to regulate neuronal migration in the cerebral cortex. In $\mathrm{crmp1} 1^{-/-}$mice, radial migration of cortical neurons was retarded. This phenotype was not observed in the sema $3 A^{-/-}$and

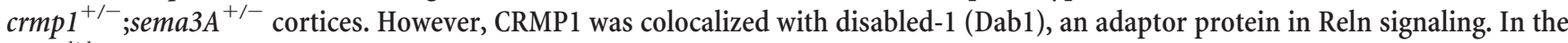
$\operatorname{Reln}^{r l / r l}$ cortex, CRMP1 and Dab1 were expressed at a higher level, yet tyrosine phosphorylated at a lower level. Loss of $\operatorname{crmp} 1$ in a dab1 heterozygous background led to the disruption of hippocampal lamination, a Reeler-like phenotype. In addition to axon guidance, CRMP1 regulates neuronal migration by mediating Reln signaling.

Key words: CRMP; Reln; Dab1; tyrosine phosphorylation; neuronal migration; cerebral cortex

\section{Introduction}

The development of the neocortex has been of keen interest, because the cortex is uniquely mammalian and forms the basis for higher function. The neocortex consists of six layers of neurons that have distinct morphological and functional identities. The development of these neuronal layers involves the migration of neurons to their final laminar positions (Bielas et al., 2004).

Reelin (Reln) is a secreted protein that is involved in neuronal migration (Lambert de Rouvroit and Goffinet, 1998). During Reln binding to ApoER2/VLDLR receptors, the cytoplasmic adaptor disabled-1 (Dab1) becomes phosphorylated on tyrosine residues by Src-type tyrosine kinases (Hiesberger et al., 1999; Howell et al., 1999a; Bock and Herz, 2003). Perinatal lethality caused by widespread defects in neuronal migration during CNS development is evident in mice deficient for cyclin-dependent kinase 5 (Ohshima et al., 1996). Although how these molecules

\footnotetext{
Received Sept. 30, 2006; revised Nov. 15, 2006; accepted Nov. 17, 2006.

This work was supported by Core Research for Evolutional Science and Technology of the Japan Science and Technology Corporation (K.T., Y.G.), Grants-in-Aid for Scientific Research in a Priority Area from the Ministry of Education, Science, Sports and Culture (Y.G.), and the Yokohama Medical Foundation (N.Y., Y.G.). We thank Dr. K. Nakajima and Dr. H. Tabata for helpful discussions about the analysis of neuronal migration. We thank Dr. M. Ogawa for helpful discussions about the analysis of Reelin signaling cascade. We thank Dr. B. Howell for his kind gift of antibody. We also thank Y. Sugiyama, T. Okada, T. Ueda, T. Hida, K. Ugajin, and M. Miyazaki for technical assistance.

Correspondence should be addressed to Yoshio Goshima, Department of Molecular Pharmacology and Neurobiology, Yokohama City University Graduate School of Medicine, Fuku-ura 3-9, Kanazawa Ward, Yokohama City 236-0004, Japan. E-mail: goshima@med.yokohama-cu.ac.jp.

D0I:10.1523/JNEUROSCI.4276-06.2006

Copyright $\odot 2006$ Society for Neuroscience $\quad$ 0270-6474/06/2613357-06\$15.00/0
}

regulate neuronal migration remains obscure, several intracellular molecules, including Lis 1 (PAFAH1b1), doublecortin, Nudel, microtubule associated protein (MAP)-1B, MAP-2, and the small GTPase Racl, have been implicated as mediators of these molecules and are involved in cytoskeletal organization (Gupta et al., 2002).

Collapsin response mediator protein (CRMP) was identified as a signaling molecule of Sema3A (Goshima et al., 1995). CRMPs are now known to be composed of five homologous cytosolic proteins; all of the family proteins are phosphorylated and are highly expressed in developing and adult nervous systems (Wang and Strittmatter, 1996; Fukada et al., 2000; Inatome et al., 2000; Yuasa-Kawada et al., 2003). CRMPs also mediate other signaling, such as NT3, and are involved in many aspects of neuronal cell development by regulating cytoskeletal organization (Goshima et al., 1995, 2002; Quach et al., 2004; Arimura and Kaibuchi, 2005; Uchida et al., 2005; Yoshimura et al., 2005). However, in vivo roles of CRMPs are mostly unknown.

To elucidate in vivo roles of CRMP 1 in the development of the CNS, we have generated $\mathrm{crmp1}^{-1-}$ mice (Charrier et al., 2006). We demonstrated that CRMP1 mediates Sema3A signaling in vivo, which is involved in spine maturation (N. Yamashita, A. Morita, Y. Uchida, F. Nakamura, H. Usui, M. Taniguchi, J. Honnorat, P. Kolattukudy, N. Thomasset, K. Takei, T. Takahashi, and Y. Goshima, unpublished observations). Intense crmp1 expression is observed in the cerebral cortex at the embryonic day 16.5 (E16.5), the period of neuronal migration (Bielas et al., 2004). In 
the present study, we investigated whether CRMP1 plays a role in neuronal migration in the cerebral cortex. We found that neuronal migration was retarded in the $\mathrm{crmpl}^{-/-}$cerebral cortex. In embryonic Reln ${ }^{r l / r l}$ cortex, CRMP1 was tyrosine phosphorylated at a lower level and expressed at a higher level when compared with $\operatorname{Reln}^{r l /+}$. Furthermore, loss of $c r m p 1$ in a dab1 heterozygous background led to the disruption of hippocampal lamination, a Reeler-like phenotype. We propose that CRMP1 is involved in radial neuronal migration through Reln signaling.

\section{Materials and Methods}

Materials. 5-Bromo-2'-deoxyuridine (BrdU) was purchased from GE Healthcare (Piscataway, NJ). Anti-Dab1 (B3; rabbit polyclonal) antibody was a kind gift from B. Howell (National Institute of Neurological Disorders and Stroke, Bethesda, MD). Monoclonal antibodies against CRMP1 (2C6G and 2E7G) were raised as described previously (N. Yamashita, A. Morita, Y. Uchida, F. Nakamura, H. Usui, M. Taniguchi, J. Honnorat, P. Kolattukudy, N. Thomasset, K. Takei, T. Takahashi, and Y. Goshima, unpublished observations). Other antibodies used were antiBrdU (mouse monoclonal; MBL, Nagoya, Japan), anti- $\beta$-actin (mouse monoclonal; Sigma, St. Louis, MO), anti-Myc (9E10; mouse monoclonal; Sigma), anti-MAP-2 (2a $+2 b)$ (mouse monoclonal; Sigma), antiNestin (mouse monoclonal; Chemicon, Temecula, CA), anti-p-Tyr (PY99; mouse monoclonal; Santa Cruz Biotechnology, Santa Cruz, CA), Cy3-labeled goat anti-Armenian hamster (Jackson ImmunoResearch, West Grove, PA), and Alexa 488-labeled goat anti-rabbit (Invitrogen, Cergy Pontoise, France).

Mutant mice. reeler B6C3Fe mice were from The Jackson Laboratory (Bar Harbor, ME). yotari mice were spontaneous mutants at the dabl allele (Yoneshima et al., 1997). sema3A and crmp1 mutant mice were generated as described previously (Taniguchi et al., 1997; Charrier et al., 2006). Genotypes of the offspring of all mutant mice were assessed using PCR, as described previously (D'Arcangelo et al., 1997; Kojima et al., 2000; Sasaki et al., 2002; Charrier et al., 2006). Mice were housed in the standard mouse facility and fed with an autoclaved diet and water. All procedures were performed according to the guidelines outlined by the institutional Animal Care and Use Committee of the Yokohama City University Graduate School of Medicine. Throughout the experimental procedures, all efforts were made to minimize the number of animals used and their suffering.

Immunoblot analysis and immunoprecipitation. Brain samples were homogenized in immunoprecipitation (IP) buffer [20 mm Tris- $\mathrm{HCl}, \mathrm{pH}$ 8.0, $150 \mathrm{~mm} \mathrm{NaCl}, 1 \mathrm{~mm}$ EDTA, $10 \mathrm{~mm} \mathrm{NaF}, 1 \mathrm{~mm} \mathrm{Na}_{3} \mathrm{VO}_{4}, 1 \%$ Nonidet P-40, $50 \mu \mathrm{M} \rho$-APMSF ( $\rho$-amidinophenylmethanesulfonyl fluoride), and $10 \mu \mathrm{g} / \mathrm{ml}$ of aprotinin]. The lysates were centrifuged at $1200 \mathrm{rpm}$ for 15 $\min$ at $4^{\circ} \mathrm{C}$, and supernatants were normalized for total protein concentrations. The samples were then used for immunoblot analysis of antiCRMP1 (2E7G; 1:2500), anti- $\beta$-actin (1:5000), anti-Dab1 (1:500), antiMAP-2 $(2 \mathrm{a}+2 \mathrm{~b})(1: 2000)$, and anti-Nestin (1:1000) antibodies. To detect the tyrosine phosphorylation of CRMP1, the samples were incubated with $1 \mu \mathrm{g}$ of anti-CRMP1 (2E7G) antibody overnight at $4^{\circ} \mathrm{C}$, followed by additional incubation with protein G-Sepharose (GE Healthcare) for $2 \mathrm{~h}$ at $4^{\circ} \mathrm{C}$. After washing three times with IP buffer, the samples were used for immunoblot analysis of anti-CRMP1 (2E7G) and anti-pTyr (1:5000) antibodies.

In vivo phosphorylation assay. HEK293T cells were seeded at $2.0 \times 10^{5}$ cells/well in a six-well plate. One day later, the cells were transfected with CRMP1-Myc with or without the wild-type, constitutive-active or dominant-negative form of Fyn expression vector using Fugene6 transfection reagent (Roche, Meylan, France). After $24 \mathrm{~h}$, cells were lysed by IP buffer and then immunoprecipitated with $1 \mu \mathrm{g}$ of anti-Myc antibody. The samples were used for immunoblot analysis of anti-Myc (1:2500) and anti-p-Tyr antibodies.

Immunohistochemistry. Cryostat brain sections (15 $\mu \mathrm{m}$ thick) were treated with $0.1 \%$ Triton X-100 in TBS with Tween 20 (TBST) for $10 \mathrm{~min}$ at room temperature. Immunostaining was performed according to standard protocols using anti-CRMP1 (2C6G; 1:1000) and anti-Dab1 (1:100) antibodies. Hydrolyzed, paraffin wax-embedded sections $(6 \mu \mathrm{m}$ thick) were used for immunohistochemistry of anti-MAP-2 $(2 \mathrm{a}+2 \mathrm{~b})$ (1:200) and anti-Nestin (1:100) antibodies. Slides were analyzed using a laser-scanning microscope (LSM510) with a water-immersed objective at $40 \times$ (C-Apochromat/1.2W corr) equipped with an Axioplan 2 imaging microscope (Carl Zeiss, Jena, Germany).

BrdU-labeling analysis. For birth-dating analysis, cells were labeled with $\mathrm{BrdU}(30 \mathrm{mg} / \mathrm{kg})$ in the E14.5 or E16.5 neocortical wall. Pups were killed at E18.5, postnatal day 3 (P3) or P10, and brains were fixed in $4 \%$ paraformaldehyde for paraffin wax-embedded sectioning. Hydrolyzed, paraffin wax-embedded sections $\left(6 \mu \mathrm{m}\right.$ thick) were heat-treated at $120^{\circ} \mathrm{C}$ for $20 \mathrm{~min}$ in $10 \mathrm{~mm}$ sodium citrate buffer, $\mathrm{pH}$ 6.0. Sections were then treated with $0.1 \%$ Triton X-100 in TBST for 10 min and with $1.5 \mathrm{~N} \mathrm{HCl}$ for $30 \mathrm{~min}$ at room temperature. Immunostaining was performed according to standard protocols using anti-BrdU antibody (1:1000). Slides were analyzed using Olympus (Tokyo, Japan) IX-71 microscopy using a $10 \times$ objective. For quantitative measurements, comparable sections were chosen at the somatosensory cortex, which was divided into 10 horizontal bins from the superficial to the deep, and labeled nuclei in each bin were counted (Teng et al., 2001).

Statistical significance. Data are shown as mean \pm SEM. The statistical significance of the results was analyzed using a Student's $t$ test.

\section{Results}

\section{Neuronal migration in $\mathrm{crmpl}^{-/-}$cortex}

To examine neuronal migration, we performed BrdU birthdating analysis in the $c r m p 1^{-/-}$cerebral cortex. In the brains of P10 injected at E14.5 (P10-BrdU-E14.5) $\mathrm{crmp}^{+/-}$cortex, most labeled neurons were positioned in the deep layers of the cerebral cortex destined to form layers IV and V. In $c r m p 1^{-1-}$ mice, the majority of labeled cells were positioned at layers IV and V. The percentage of labeled cells positioned in those regions, however, was decreased, and the percentage of other regions was increased (Fig. 1A). A similar phenotype was also observed in the P10BrdU-E16.5 $\mathrm{crmp1}^{-1-}$ cortex. Most labeled neurons were positioned in the upper layers of the cortex, which were destined to form layers II and III in $\mathrm{crmp}^{+/-}$cortex. However, the percentage of correctly positioned neurons was decreased, whereas the percentage of the cells in the other regions tended to be increased in $\mathrm{crmp}^{-/-}$mice (Fig. $1 \mathrm{~B}$ ). We also investigated E18.5-BrdUE14.5 and P3-BrdU-E16.5 $\mathrm{crmpl}^{+/-}$and $\mathrm{crmp1} 1^{-/-}$mouse cortices to observe the radial migration. In both brains, the retarded phenotype of neuronal migration was observed in the $\mathrm{crmp} 1^{-1-}$ cortex (data not shown). We next investigated neuronal differentiation and survival in the $c r m p 1^{-1-}$ cortex. At E16.5, apoptotic cells were rarely observed by terminal deoxynucleotidyl transferase-mediated biotinylated UTP nick end labeling staining. There was no difference in the proliferation of cortical progenitor cells between $\mathrm{crmp} 1^{-/-}$and $\mathrm{crmp} 1^{+/-}$cortices by BrdU proliferative analysis (data not shown). Furthermore, immunoreactivity and protein expression levels of Nestin and MAP-2 (2a $+2 \mathrm{~b})$, markers of dividing precursors and of matured neurons, respectively, in E16.5 $\mathrm{crmpl}^{-1-}$ mice, were not different from those in $c r m p 1^{+/-}$mice (Fig. $1 C, D$ ). These results indicate that CRMP1 plays a major role in neuronal cells at the postmitotic phase.

We next investigated whether a Sema3A-CRMP1 signaling cascade was also involved in neuronal migration in the cerebral cortex. Because most of the sema3 $A^{-1-}$ pups died after birth, we performed only E18.5-BrdU-E14.5 analysis in the sema3 $A^{-/-}$ cortex. We did not observe any differences between $w t$, sema $3 A^{+/-}$, and sema3 $A^{-1-}$ in the E18.5-BrdU-E14.5 cortices (Fig. 2A). In addition, double heterozygous crmpl and sema3A mice did not show any differences compared with $\mathrm{crmpl}^{+/-}$ mice in the E18.5-BrdU-E14.5, P10-BrdU-E14.5, P3-BrdUE16.5, and P10-BrdU-E16.5 cortices (Fig. 2B,C) (data not 
A

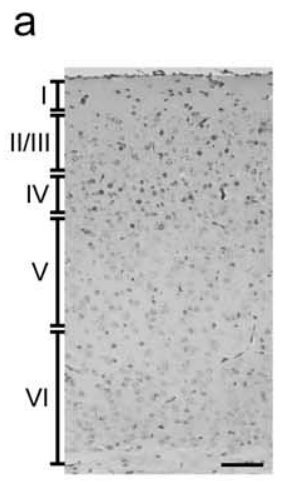

$\mathrm{crmp}^{1+-}$

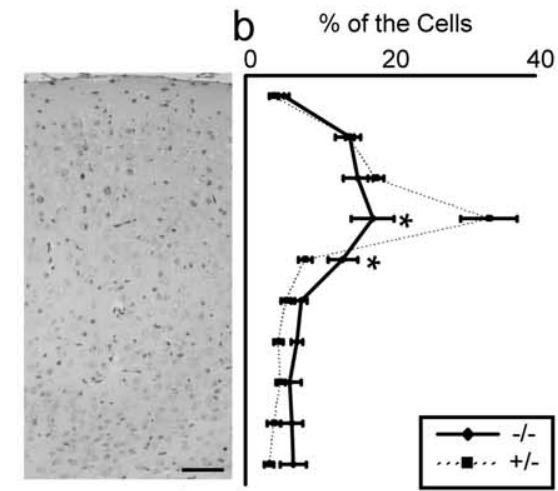

crmp1-/

B

\section{P10-BrdU-E14.5}

a

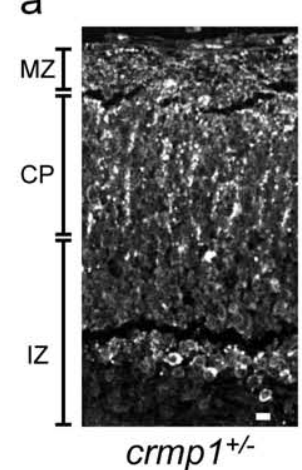

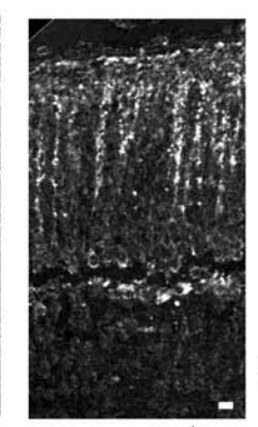

crmp1-

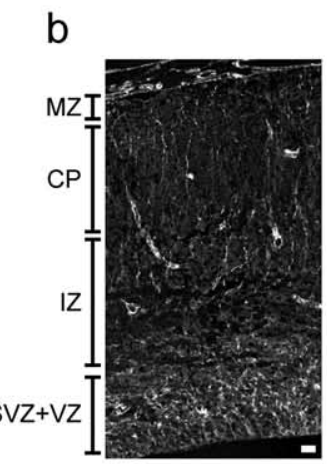

$\mathrm{crmp}^{+/-}$

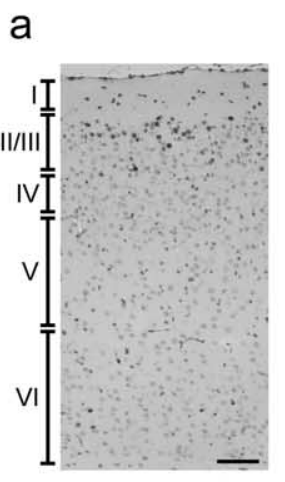

crmp $1^{+-}$

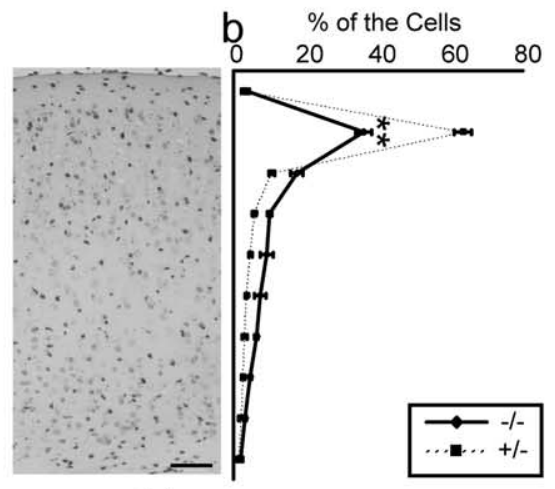

crmp1-

\section{P10-BrdU-E16.5}
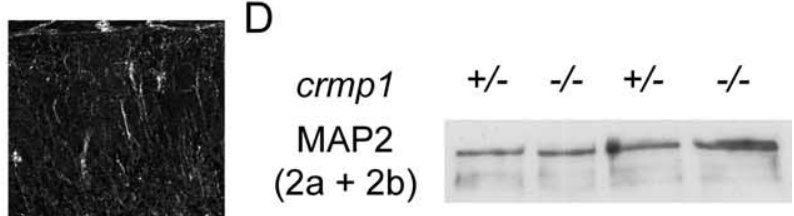

Nestin

$\beta$-actin

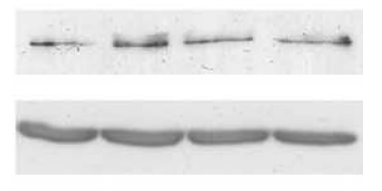

Figure 1. Abnormally positioned neurons in the $\mathrm{crmp} 1^{-/-}$cerebral cortex. A, Distribution of cells in the P10 -BrdU-E14.5 $\mathrm{crmp} 1^{+/-}$or $\mathrm{Crmp} 1^{-1-}$ coronal cortical sections. The rate of the BrdU-labeled nuclei of each bin (see Materials and Methods) is shown in $\boldsymbol{b}$. B, Distribution of cells in the P10 -BrdU-E16.5 $\mathrm{crmp1}^{+/-}$and $\mathrm{crmp1} 1^{-1-}$ coronal cortical sections. The rate of the BrdU-labeled nuclei of each bin is shown in $\boldsymbol{b}$. In all cases, three littermates of each genotype were used for quantification. $\boldsymbol{C}, \mathrm{E} 16.5 \mathrm{crmp} 1^{+/-}$or $\mathrm{crmp} 1^{-/-}$coronal cortical sections immunostained with anti-MAP-2 $(2 \mathrm{a}+2 \mathrm{~b})(\boldsymbol{a})$ and anti-Nestin $(\boldsymbol{b})$ antibodies. D, Expression levels of MAP-2 $(2 \mathrm{a}+2 \mathrm{~b})$ and Nestin at E16.5 $\mathrm{crmp}^{+/-}$or $\mathrm{crmp}^{-/-}$mouse cortex lysates from two individual embryos of each genotype. Equal amounts of protein were analyzed, as indicated by the loading control ( $\beta$-actin). Cortical layers are shown on the left. Scale bars: $\boldsymbol{A}, \boldsymbol{B}, 100 \mu \mathrm{m} ; \boldsymbol{C}, 10 \mu \mathrm{m}$. MZ, Marginal zone; $\mathrm{CP}$, cortical plate; IZ, intermediate zone; SVZ, subventricular zone; VZ, ventricular zone. ${ }^{*} p<0.05,{ }^{* *} p<0.01$ compared with the corresponding value in $\mathrm{crmp}^{+/-}$.

shown). These results suggest that CRMP1 mediates some signaling molecules other than Sema3A in cortical layer formation.

\section{CRMP1 is involved in Reln signaling}

In radial migration in the cerebral cortex, tyrosine phosphorylation of Dab1 by a Reln signaling cascade has been shown to be essential. Biochemical analysis has revealed a decreased tyrosine phosphorylation of Dab1 in the Reln ${ }^{r l / r l}$ cortex (Howell et al., 1999a, 2000). One of the tyrosine kinases that is involved in phosphorylation of Dabl is Fyn, an Src-type tyrosine kinase (Bock and Herz, 2003). Because we found that CRMP1 was tyrosine phosphorylated by Fyn in HEK293T cells (Fig. 3A), we assumed that CRMP1 was one of the substrates phosphorylated by tyrosine kinases through a Reln signaling cascade. To examine this hypothesis, we immunoprecipitated $\operatorname{Reln}^{r l /+}$ and $\operatorname{Reln}^{r l / r l}$ brain lysates with anti-CRMP1 antibody and analyzed tyrosine phosphorylation levels of CRMP1 by anti-phospho-tyrosine antibody. The phosphorylation of CRMP1 at tyrosine residue(s) was detected in the brain lysate from $\operatorname{Reln}^{r l /+}$ mice. The level of tyrosine phosphorylation of CRMP1 was decreased in the Reln ${ }^{r l / r l}$ cortex (Fig. 3B). The relative level of tyrosine phosphorylation of CRMP1 in Reln ${ }^{r l / r l}$ normalized by the amount of immunoprecipitated CRMP1 in $\operatorname{Reln}^{r l /+}(100.0 \pm 25.0)$ was $38.8 \pm 5.2 \%(N=3$; $p<0.05)$. In addition, the expression of CRMP1 showed a higher level in $\operatorname{Reln}^{r l / r l}$ than in $\operatorname{Reln}^{r l /+}$ mice. The CRMP1 expression was increased to a lesser extent than was the Dabl expression in the brain lysates from $\operatorname{Reln}^{r l / r l}$ mice (Fig. 3C). The relative amount of CRMP1 normalized by $\beta$-actin in $\operatorname{Reln}^{r l /+}$ and $\operatorname{Reln}^{r l / r l}$ was $100.0 \pm 11.8$ and $155.8 \pm 17.3 \%$, respectively $(N=3 ; p<0.05)$.

In $\operatorname{Reln}^{r l / r l}$ cortex, reduced Dab1 expression is observed at superplate, whereas its increased expression is observed at cortical plate (Rice et al., 1998). We examined the protein expression pattern of CRMP1 in Reln ${ }^{r l /+}$ and Reln ${ }^{r l / r l}$ cortices. Intense antiCRMP1 and Dab1 immunoreactivities were observed at the marginal zone in $\operatorname{Reln}^{r l /+}$ cortex, whereas reduced immunoreactivities were observed at superplate in $\operatorname{Reln}^{r l / r l}$ cortex. In addition, increased immunoreactivities of anti-CRMP1 and Dab1 at the cortical plate were also observed in $\operatorname{Reln}^{r l / r l}$ cortex. Increased CRMP1 expression was observed in some neurons, whereas increased Dab1 expression was in almost all of the neurons of the cortical plate in Reln $^{r l / r l}$ mice (Fig. 3D).

We further attempted to analyze the genetic interaction with crmpl and dab1; we used yotari mice, one of the spontaneous mutants of dab1. Nissl staining of the brain at P10 revealed a disrupted hippocampal lamination in the loss of crmpl in a dabl heterozygous background $\left(\mathrm{crmpl} 1^{-/-} ; d a b 1^{\text {yot/+ }}\right)$, one of the 
A

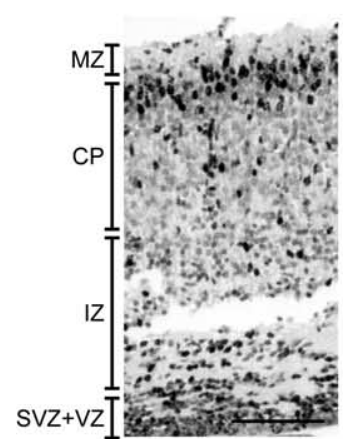

wt

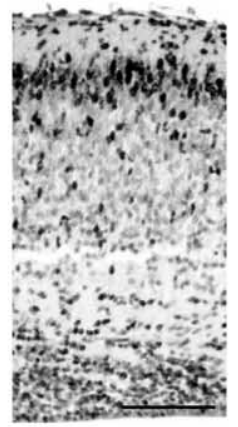

sema3 $A^{+/-}$

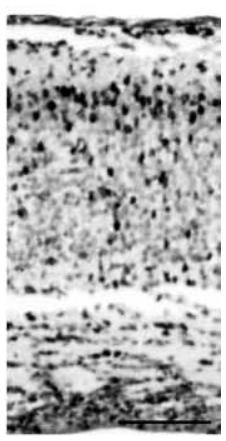

sema3 $A^{-\alpha}$
B

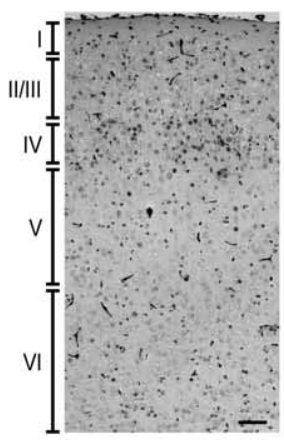

$\mathrm{crmp}^{+/-}$

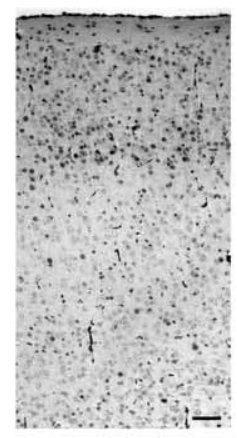
crmp $^{+/-}$
sema3 $^{+/}$

P10-BrdU-E14.5

C

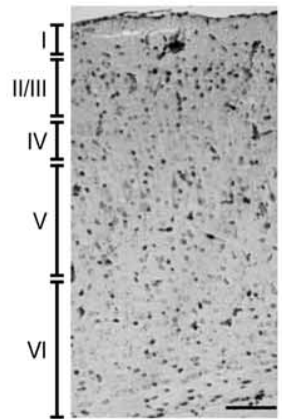

crmp $^{+/-}$

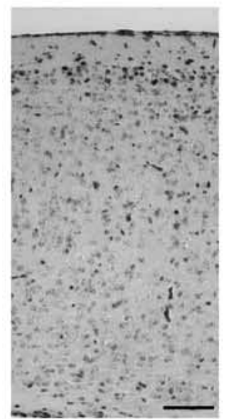

crmp $^{+/-}$-
semaA

P10-BrdU-E16.5

Figure 2. Observation of BrdU birth-dating analysis in sema3 $A^{-/-}$and sema3 $A^{+/-}$; $\mathrm{Crmp}^{+/-}$cortices. $\boldsymbol{A}$, Distribution of cells in the E18.5-BrdU-E14.5 $\mathrm{wt}$, sema3 $\mathrm{A}^{+/-}$, and sema3 $A^{-1-}$ coronal cortical sections. MZ, Marginal zone; CP, cortical plate; IZ, intermediate zone; SVZ, subventricular zone; VZ, ventricular zone. $B$, Distribution of cells in the P10 -BrdU$\mathrm{E} 14.5 \mathrm{Crmp}^{+/-}$and $\mathrm{Crmp}^{+/-} ;$;sema3 $\mathrm{A}^{+/-}$coronal cortical sections. C, Distribution of cells in the P10 - BrdU-E16.5 $\mathrm{Crmp}^{+/-}$and $\mathrm{Crmp} 1^{+/-}{ }_{;}$;sema $3 \mathrm{~A}^{+/-}$coronal cortical sections. Cortical layers are shown on the left. Scale bar, $100 \mu \mathrm{m}$.

Reeler-like phenotypes (Fig. 3E). This phenotype was not observed in $\mathrm{crmpl}^{-/-}$and dab1 $1^{\text {yot/+}}$ hippocampus (Fig. 3E) (Assadi et al., 2003), implying that CRMP1 and Dab1 were synergistically involved in Reln signaling for neuronal migration.

\section{Discussion}

We provide, for the first time, evidence that CRMP1 is involved in radial neuronal migration through Reln signaling in the developing cerebral cortex. In Reln ${ }^{r l / r l}$ cortex, CRMP1 as well as Dab1, an adaptor molecule in the transduction of the Reln signal, were expressed at a higher level, yet these were tyrosine phosphorylated at a lower level. Loss of $\mathrm{crmp} 1$ in a dabl heterozygous background led to the disruption of hippocampal lamination, a typical Reeler-like phenotype.

In the $\mathrm{crmpl}^{-1-}$ mouse cortex, retardation in neuronal migration was observed by BrdU birth-dating analysis when compared with the $\mathrm{crmpl}^{+/-}$cerebral cortex (Fig. 1) (data not shown). It is possible that Sema3A regulates neuronal migration in the developing cerebral cortex. Indeed, Sema3A regulates the tangential migration of GABAergic neurons from ganglionic eminence to the cerebral cortex (Marin et al., 2001; Tamamaki et al., 2003). Expression of $n r p 1$ and sema3A were also observed in the cerebral cortex at E16.5 (Kawakami et al., 1996; Skaliora et al., 1998). However, it appears that Sema3A signaling is not involved in radial migration during the period of cortical layer formation, because the retarded phenotype in radial neuronal migration was not seen in either the sema $3 A^{-/-}$or double heterozygotes of crmpl and sema3A mouse cortices (Fig. 2). Consistently, the overall expression pattern of nrp1 was different from that of crmpl in the cerebral cortex at E16.5 (N. Yamashita, A. Morita, Y. Uchida, F. Nakamura, H. Usui, M. Taniguchi, J. Honnorat, P. Kolattukudy, N. Thomasset, K. Takei, T. Takahashi, and Y. Goshima, unpublished observations).

In contrast, the expression pattern of $c r m p 1$ was similar to that of dab1. We clearly showed that the expression of CRMP1 was increased in the Reln ${ }^{r l / r l}$ cortex and reduced tyrosine phosphorylation of CRMP1 (Fig. 3B,C). Furthermore, the protein expression pattern of CRMP1 was also similar to that of Dab1 at the marginal zone and the cortical plate. The expression level of CRMP1 was decreased at superplate and increased at the cortical plate in the $\operatorname{Reln}^{r l / r l}$ cortex, respectively (Fig. 3D). In adult Reln ${ }^{r l / r l}$ cerebellum, the number of granule cells was reduced, and transient reduction of granule cells was observed in $\mathrm{crmp1}^{-/-}$cerebellum (Rice et al., 1998; Charrier et al., 2006). We found that loss of crmp 1 in a dab1 heterozygous background led to the disruption of hippocampal lamination, a Reeler-like phenotype (Fig. 3E). Because the mutations in Reln pathway genes cause distinctive abnormalities in many laminated brain regions, known as the Reeler phenotype (D'Arcangelo et al., 1999; Hiesberger et al., 1999; Howell et al., 1999b), these findings strongly suggest that CRMP1 mediates Reln signaling to regulate neuronal migration.

We assumed that Reln regulates neuronal migration through tyrosine phosphorylation of CRMP1 because decreased tyrosine phosphorylation of Dab1 is observed in the Reln ${ }^{r l / r l}$ cortex (Howell et al., 1999a, 2000), and animals expressing the nonphosphorylated Dab1 protein have a phenotype similar to the dab1 null mutant (Howell et al., 2000). Fyn and Fes tyrosine kinases have also been proposed to be signaling components of Sema3A (Mitsui et al., 2002; Sasaki et al., 2002). We found that when CRMP1 and Fyn were introduced into HEK293T cells, CRMP1 was phosphorylated at tyrosine residue(s) (Fig. $3 A$ ). We tried to detect phosphorylation of CRMP1 at tyrosine residue(s) in the cultured cortical neurons treated with Reln. Up to now, we have not yet obtained clear evidence for tyrosine phosphorylation of CRMP1 after Reln stimulation. The important finding is, however, that the level of tyrosine phosphorylation of CRMP1 was decreased in the $\operatorname{Re}^{r} n^{r l / r l}$ cortex (Fig. $3 B$ ). Additional studies are required to 
A

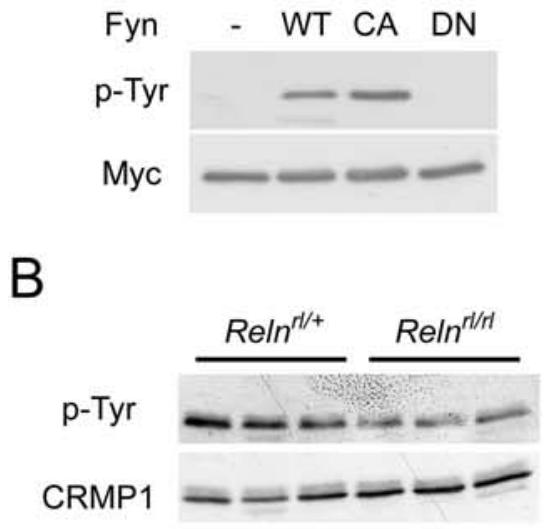

C

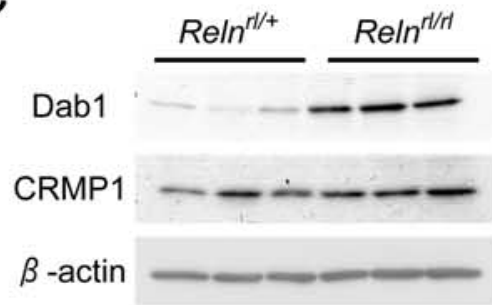

$\mathrm{D}$

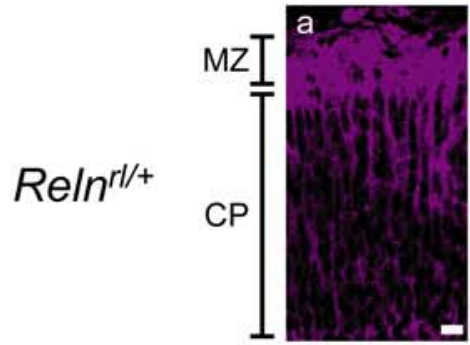

CRMP1

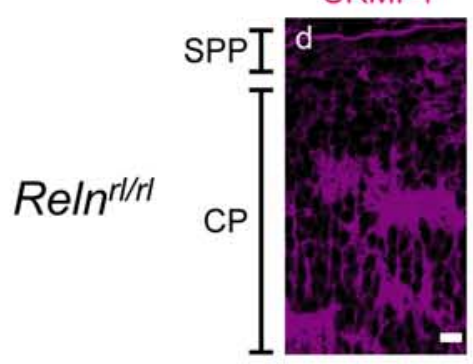

CRMP1

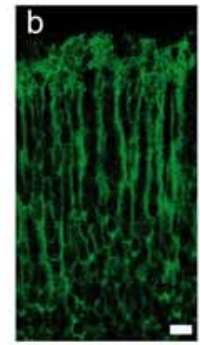

Dab1

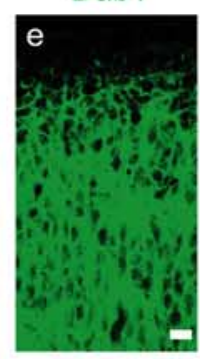

Dab1

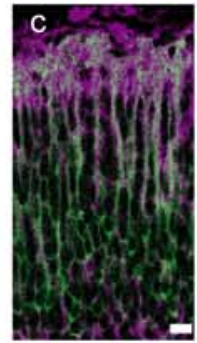

CRMP1/Dab1

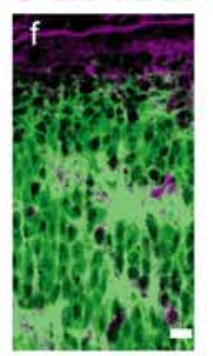

CRMP1/Dab1
$E$

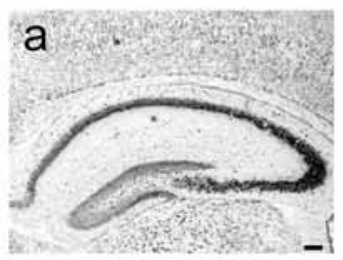

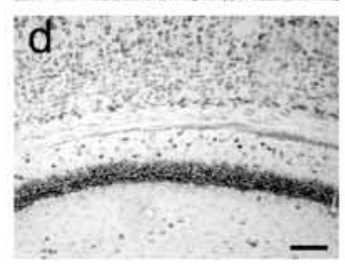

$\mathrm{crmp}^{-/-}$
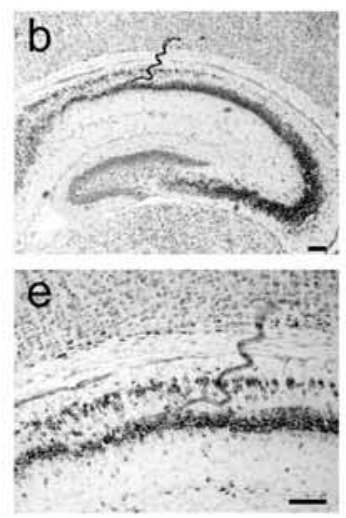

crmp $1^{-/-}$
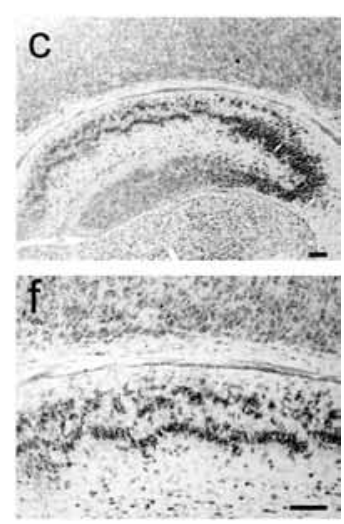

crmp $1^{\%}$;

Figure 3. Expression and tyrosine phosphorylation of CRMP1 in Rel ${ }^{r / 1 / r l}$ cortex and the genetic interaction between crmp 1 and dab1 in the hippocampus. A, Tyrosine phosphorylation of CRMP1 by Fyn. CRMP1-Myc was introduced with or without the wild-type (WT), constitutive-active (CA), or dominant-negative (DN) form of Fyn in HEK293T cells. Immunoprecipitation with anti-Myc antibody was performed and was thereafter immunoblotted with anti-p-Tyr and anti-Myc antibodies. B, Tyrosine phosphorylation of CRMP1 in Rel$h^{r / /+}$ and Rel$/ n^{r / / r l}$ lysates from mouse cortex at E16.5. Immunoprecipitation with anti-CRMP1

delineate phosphorylation site(s) of CRMP1 and its functional significance in Reln signaling.

The presence of Reln correlates with reduced Dab1 protein levels during embryonic development (Rice et al., 1998; Howell et al., 1999a). Our study showed that the expression of CRMP1 was higher in $\operatorname{Reln}^{r l / r l}$ cortex compared with $\operatorname{Reln}^{r l /+}$ mice (Fig. 3C), suggesting that Reln regulates CRMP1 protein levels in the cerebral cortex. This further indicates that CRMP1 possesses a biochemical property similar to Dab1. Interestingly, some neurons exhibited an increased immunoreactivity of CRMP1 in the Reln ${ }^{r l / r l}$ cortical plate at E16.5, whereas Dab1 accumulation was observed in almost all neurons in the cortical plate (Fig. 3D). This result suggests that CRMP1 may regulate migration of a subset of the cortical neurons. The neurons exhibiting increased immunoreactivity of CRMP1 in the $\operatorname{Reln}^{r l / r l}$ cortex were distributed throughout the cerebral cortex (Fig. 3D). Consistent with this observation, $c r m p 1^{-/-}$showed a retarded migration phenotype in both the upper and deep layers of the cerebral cortex (Fig. 1A,B). These findings suggest that neurons in which CRMP1 may regulate their migration are composed of a heterogeneous subpopulation, being unrelated to a specific cortical layer. The characterization of the CRMP1-positive neurons remains to be determined. The expression pattern of another CRMP family member, crmp2, was almost similar to that of crmp1 (Wang and Strittmatter, 1996). Both CRMP1 and CRMP2 are involved in mediating Sema3A signaling (Uchida et al., 2005). These findings are consistent with a mild defect in neuronal migration in the crmp $1^{-1-}$ cortex, rather than in the $\operatorname{Reln}^{r l / r l}$ cerebral cortex. Indeed, disruption of a single gene, having overlapping func-

$\leftarrow$

antibody was performed and was thereafter immunoblotted with anti-p-Tyr and anti-CRMP1 antibodies. C, Expression levels of CRMP1 at E16.5 Reln ${ }^{r / /+}$ and Reln ${ }^{r / / r l}$ brain lysates. Immunoblot analysis of anti-CRMP1 and anti-Dab1 antibodies of three individual embryos of each genotype was performed. Equal amounts of protein were analyzed, as indicated by the loading control ( $\beta$-actin). $\boldsymbol{D}$, Immunohistochemistry with anti-CRMP1 (magenta) and anti-Dab1 (green) antibodies in E16.5 $\operatorname{Re}^{r / 1 /+}(\boldsymbol{a}-\boldsymbol{c})$ and $\operatorname{Re}^{r l / r l}(\boldsymbol{d}-\boldsymbol{f})$ coronal cortical sections. Cortical layers are shown on the left. MZ, Marginal zone; $C$, cortical plate; SPP, superplate. E, Nissl staining of the brains at P10 of $\mathrm{Crmp}^{-1-}(\boldsymbol{a}, \boldsymbol{d})$, $\mathrm{crmp1}^{-1-} ; \mathrm{dab} 1^{\text {yot/ }+}(\boldsymbol{b}, \boldsymbol{e})$, and $\mathrm{crmp} 1^{-1-} ;$ dab $7^{\text {yot/yot }}$ $(\boldsymbol{c}, \boldsymbol{f})$ mice. Coronal sections of the hippocampus region are presented. Magnified images of the CA1 region in $\boldsymbol{a}, \boldsymbol{b}$, and $\boldsymbol{c}$ are shown in $\boldsymbol{d}, \boldsymbol{e}$, and $\boldsymbol{f}$, respectively. Scale bars: $\boldsymbol{D}, 10 \mu \mathrm{m} ; \boldsymbol{E}$, $100 \mu \mathrm{m}$. 
tions, sometimes does not result in any phenotypic defects in the mutant animals (Kuo et al., 2005). The combined disruption with other CRMP family genes will therefore tell us the exact roles of CRMP1 in the developing cerebral cortex.

This is the first evidence for an important role of CRMP1 in Reln signaling. It appears that the CRMP family is involved in cytoskeletal organization by receiving various extracellular cues that contribute to neuronal development and maturation.

\section{References}

Arimura N, Kaibuchi K (2005) Key regulators in neuronal polarity. Neuron 48:881-884.

Assadi AH, Zhang G, Beffert U, McNeil RS, Renfro AL, Niu S, Quattrocchi CC, Antalffy BA, Sheldon M, Armstrong DD, Wynshaw-Boris A, Herz J, D'Arcangelo G, Clark GD (2003) Interaction of Reelin signaling and Lis1 in brain development. Nat Genet 35:270-276.

Bielas S, Higginbotham H, Koizumi H, Tanaka T, Gleeson JG (2004) Cortical neuronal migration mutants suggest separate but intersecting pathways. Annu Rev Cell Dev Biol 20:593-618.

Bock HH, Herz J (2003) Reelin activates SRC family tyrosine kinases in neurons. Curr Biol 13:18-26.

Charrier E, Mosinger Jr B, Meissirel C, Aguera M, Rogemond V, Reibel S, Salin P, Chounlamountri N, Perrot V, Belin M, Goshima Y, Honnorat J, Thomasset N, Kolattukudy P (2006) Transient alterations in granule cell proliferation, apoptosis and migration in post-natal developing cerebellum of CRMP1 ${ }^{-I-}$ mice. Genes Cells, 11:1337-1352.

D’Arcangelo G, Nakajima K, Miyata T, Ogawa M, Mikoshiba K, Curran T (1997) Reelin is a secreted glycoprotein recognized by the CR-50 monoclonal antibody. J Neurosci 17:23-31.

D’Arcangelo G, Homayouni R, Keshvara L, Rice DS, Sheldon M, Curran T (1999) Reelin is a ligand for lipoprotein receptors. Neuron 24:471-479.

Fukada M, Watakabe I, Yuasa-Kawada J, Kawachi H, Kuroiwa A, Matsuda Y, Noda M (2000) Molecular characterization of CRMP5, a novel member of the collapsin response mediator protein family. J Biol Chem 275:37957-37965.

Goshima Y, Nakamura F, Strittmatter P, Strittmatter SM (1995) Collapsininduced growth cone collapse mediated by an intracellular protein related to UNC-33. Nature 376:509-514.

Goshima Y, Ito T, Sasaki Y, Nakamura F (2002) Semaphorins as signals for cell repulsion and invasion. J Clin Invest 109:993-998.

Gupta A, Tsai LH, Wynshaw-Boris A (2002) Life is a journey: a genetic look at neocortical development. Nat Rev Genet 3:342-355.

Hiesberger T, Trommsdorff M, Howell BW, Goffinet A, Mumby MC, Cooper JA, Herz J (1999) Direct binding of Reelin to VLDL receptor and ApoE receptor 2 induces tyrosine phosphorylation of disabled-1 and modulates tau phosphorylation. Neuron 24:481-489.

Howell BW, Herrick TM, Cooper JA (1999a) Reelin-induced tryosine phosphorylation of disabled 1 during neuronal positioning. Genes Dev 13:643-648.

Howell BW, Lanier LM, Frank R, Gertler FB, Cooper JA (1999b) The disabled 1 phosphotyrosine-binding domain binds to the internalization signals of transmembrane glycoproteins and to phospholipids. Mol Cell Biol 19:5179-5188.

Howell BW, Herrick TM, Hildebrand JD, Zhang Y, Cooper JA (2000) Dab1 tyrosine phosphorylation sites relay positional signals during mouse brain development. Curr Biol 10:877-885.

Inatome R, Tsujimura T, Hitomi T, Mitsui N, Hermann P, Kuroda S, Yamamura H, Yanagi S (2000) Identification of CRAM, a novel unc-33 gene family protein that associates with CRMP3 and protein-tyrosine kinase(s) in the developing rat brain. J Biol Chem 275:27291-27302.

Kawakami A, Kitsukawa T, Takagi S, Fujisawa H (1996) Developmentally regulated expression of a cell surface protein, neuropilin, in the mouse nervous system. J Neurobiol 29:1-17.

Kojima T, Nakajima K, Mikoshiba K (2000) The disabled 1 gene is disrupted by a replacement with $\mathrm{L} 1$ fragment in yotari mice. Brain Res Mol Brain Res 75:121-127.

Kuo G, Arnaud L, Kronstad-O’Brien P, Cooper JA (2005) Absence of Fyn and Src causes a reeler-like phenotype. J Neurosci 25:8578-8586.

Lambert de Rouvroit C, Goffinet AM (1998) The reeler mouse as a model of brain development. Adv Anat Embryol Cell Biol 150:1-106.

Marin O, Yaron A, Bagri A, Tessier-Lavigne M, Rubenstein JL (2001) Sorting of striatal and cortical interneurons regulated by semaphorinneuropilin interactions. Science 293:872-875.

Mitsui N, Inatome R, Takahashi S, Goshima Y, Yamamura H, Yanagi S (2002) Involvement of Fes/Fps tyrosine kinase in semaphorin3A signaling. EMBO J 21:3274-3285.

Ohshima T, Ward JM, Huh CG, Longenecker G, Veeranna, Pant HC, Brady RO, Martin LJ, Kulkarni AB (1996) Targeted disruption of the cyclindependent kinase 5 gene results in abnormal corticogenesis, neuronal pathology and perinatal death. Proc Natl Acad Sci USA 93:11173-11178.

Quach TT, Duchemin AM, Rogemond V, Aguera M, Honnorat J, Belin MF, Kolattukudy PE (2004) Involvement of collapsin response mediator proteins in the neurite extension induced by neurotrophins in dorsal root ganglion neurons. Mol Cell Neurosci 25:433-443.

Rice DS, Sheldon M, D’Arcangelo G, Nakajima K, Goldowitz D, Curran T (1998) Disabled-1 acts downstream of Reelin in a signaling pathway that controls laminar organization in the mammalian brain. Development 125:3719-3729.

Sasaki Y, Cheng C, Uchida Y, Nakajima O, Ohshima T, Yagi T, Taniguchi M, Nakayama T, Kishida R, Kudo Y, Ohno S, Nakamura F, Goshima Y (2002) Fyn and Cdk5 mediate semaphorin-3A signaling, which is involved in regulation of dendrite orientation in cerebral cortex. Neuron 35:907-920.

Skaliora I, Singer W, Betz H, Puschel AW (1998) Differential patterns of semaphorin expression in the developing rat brain. Eur J Neurosci 10:1215-1229.

Tamamaki N, Fujimori K, Nojyo Y, Kaneko T, Takauji R (2003) Evidence that Sema3A and Sema3F regulate the migration of GABAergic neurons in the developing neocortex. J Comp Neurol 455:238-248.

Taniguchi M, Yuasa S, Fujisawa H, Naruse I, Saga S, Mishina M, Yagi T (1997) Disruption of semaphorin III/D gene causes severe abnormality in peripheral nerve projection. Neuron 19:519-530.

Teng J, Takei Y, Harada A, Nakata T, Chen J, Hirokawa N (2001) Synergistic effects of MAP2 and MAP1B knockout in neuronal migration, dendritic outgrowth, and microtubule organization. J Cell Biol 155:65-76.

Uchida Y, Ohshima T, Sasaki Y, Suzuki H, Yanai S, Yamashita N, Nakamura F, Takei K, Ihara Y, Mikoshiba K, Kolattukudy P, Honnorat J, Goshima Y (2005) Semaphorin3A signalling is mediated via sequential Cdk5 and GSK3beta phosphorylation of CRMP2: implication of common phosphorylating mechanism underlying axon guidance and Alzheimer's disease. Genes Cells 10:165-179.

Wang LH, Strittmatter SM (1996) A family of rat CRMP genes is differentially expressed in the nervous system. J Neurosci 16:6197-6207.

Yoneshima H, Nagata E, Matsumoto M, Yamada M, Nakajima K, Miyata T, Ogawa M, Mikoshiba K (1997) A novel neurological mutant mouse, yotari, which exhibits reeler-like phenotype but expresses CR-50 antigen/ Reelin. Neurosci Res 29:217-223.

Yoshimura T, Kawano Y, Arimura N, Kawabata S, Kikuchi A, Kaibuchi K (2005) GSK-3beta regulates phosphorylation of CRMP-2 and neuronal polarity. Cell 120:137-149.

Yuasa-Kawada J, Suzuki R, Kano F, Ohkawara T, Murata M, Noda M (2003) Axonal morphogenesis controlled by antagonistic roles of two CRMP subtypes in microtubule organization. Eur J Neurosci 17:2329-2343. 